\title{
From an Ancient Text to New Interpretation "The Allegory of the Cave"
}

\author{
Nissim Yonit, Pinto Iris \\ Ohalo Academic College of Education, Sciences and Sport, Katzrin, Israel \\ Email:yonitn@ohalo.ac.il, irispinto8@gmail.com
}

How to cite this paper: Yonit, N., \& Iris, P. (2017). From an Ancient Text to New Interpretation "The Allegory of the Cave". Creative Education, 8, 389-404. https://doi.org/10.4236/ce.2017.83031

Received: February 21, 2017

Accepted: March 25, 2017

Published: March 28, 2017

Copyright $\odot 2017$ by authors and Scientific Research Publishing Inc. This work is licensed under the Creative Commons Attribution International License (CC BY 4.0).

http://creativecommons.org/licenses/by/4.0/

\begin{abstract}
The research observes thinking processes of students undergoing training to become teachers. It focused on their interpretations which provide a new approach to the ancient text "The Allegory of the Cave" in Plato's Politeia (The Republic). These processes enable students to reach insights concerning the characteristics of the educator's challenges of the $21^{\text {st }}$ century. This article is based on a thorough observation of discussions in an online forum (in a Moodle environment), accompanied a lesson entitled "Introduction to philosophy of education on the timeline" that took place during the academic years 2014, 2015, 2016. In this assay we demonstrate how a discussion mediated through an online discourse explores the process of knowledge construction, collaborative learning and constructivist dialog. This is with reference to the tension between the ancient and the modern, the past and the future, tension which its intensity increases in reality changes in accelerated pace.
\end{abstract}

\section{Keywords}

Future Teachers, Online Forum, Allegory of the Cave, Augmented Analogy, Thinking Skills, Thinking Processes, Future Teacher's Skills

\section{Introduction}

The research observes thinking processes of students undergoing training to become future teachers when they interpreted and provided a new augmented analogy for the ancient text "The Allegory of the Cave" in Plato's Politeia (The Republic). These complex thinking processes have significant educational meaning in enabling students to reach insights concerning the characteristics of the educator suitable for the challenges of the 21st century. As far as could be ascertained, very few studies have dealt with such a decoding process. The article is based on a thorough observation of discussions in the forum of an online 
course that took place during the academic years 2014, 2015, 2016. This online forum (in a Moodle environment) accompanied a lesson entitled "Introduction to philosophy of education on the timeline", in Year 1 of a B.Ed. course in Education and Teaching at the Ohalo Academic College. The discussions related to the text of Plato's "Allegory of the Cave".

An allegory as a thinking process goes beyond mere simplification. Existing and developing its stereotype enrich the range of meanings through a combination of "mind with matter, symbol with narrative, simplification with history". A text that includes an allegorical tale, which provides a different and other interpretation, facilitates learning concerning the basic text (Anderson, 2008).

In this article we try to demonstrate how a discussion on "departing from the cave", mediated through an online discourse, creates collaborative learning and constructivist dialog, moving along the tension between old and the new, tension which its intensity increases in reality changes in accelerated pace. Learning within this framework appears to be a direct process of knowledge construction, conducted through the student-teachers' attempt to think about meaningful issues. We feel that the way in which the students analyzed the "Allegory of the Cave", allowed us to identify a process that Levi (2006) defined as the creation of a world of shared meaning, suitable for daily existence.

\section{The Research}

\subsection{Purposes of the Research}

To investigate whether an ancient philosophical text can be given modern interpretation by students of education and teaching in their first year of studies.

\subsection{Research Question}

What is the meaning of an ancient canonical text, the "Allegory of the Cave" for modern students training to be the educators of the future?

\subsection{Theoretical Background}

As part of the course "Introduction to the philosophy of education", a virtual forum enabled an online dialog to develop in order to share knowledge and insights (collaborative and cooperative learning). A virtual "community of learners" was formed (Pringle, 2002), and together they created layer upon layer of new knowledge based on study and discussion of ancient, international and new Israeli philosophical texts.

The online forum in which the discussion was conducted constitutes a representation, a modern analogy for a "forum", the central square for assemblies in the heart of Roman towns, which in ancient times served as a social center and the place for debate on political and governmental issues. The virtual forum, just like that Ancient Square, was positioned at the center of the course and permitted the exchange of messages, opinions and information at the touch of a keyboard. The students, who were asked to read certain articles, responded to ques- 
tions posed to them on the course forum which was dedicated to the creation of a class dialog.

The students, members of Generation Y, who constitute the majority of the population currently studying in the college, accustomed in using online infrastructures and social networks. The way they use available social applications had changed and still changing the individual and collaborative \& collective learning. The advanced technology which enables collaborative learning supports the improving educational achievements (Vygotsky, 1978; Rich, 1996) claimed that as a result of the interaction between students and small groups, students acquire skills and reach deeper understanding that they could not achieve on their own. He said that social interaction brings small groups' students to cognitive growth and improved academic achievement (Rich, 1996). Confirmation to this claim can be found in the 122 analytical studies carried out by Johnson and Johnson (1989); Sharan (1989), which found that cooperative learning distinct advantage over singular learning. Contemporary research in the field of online learning relates to a variety of means, including forums that enable online communication supporting collaborative discussion (Karacapilidis \& Papadias, 2009). It was found that a virtual environment is seen as less "threatening" and "controlled by routine conventions" than a face-to-face discussion. Moreover, it seems that this environment encourages constructivist creation of knowledge through the creation of high level cognitive products. Some scholars see students' participation in online courses as the expression of over-involvement and commitment in the context of the course contents (Dorman \& Fraser, 2009).

According to Birenbaum (2002), forums provide an advantageous environment for dialog and discussion, suitable for Socratic discourse/the seminar. Tredway (1995) explains that Socratic discourse is a discussion of moral ideas and dilemmas through work on and analysis of some sort of text. The quality of the discourse depends on the speakers' consideration of each other, and the components of discussion include: expression of ideas, posing questions and expressing doubt, leading to understandings and learning another "truth" or alternative knowledge. Discourse of this kind leads the participants to the creation of meaning, deep thinking, doubt and a new different consideration of ideas. The results of the discussion include development of knowledge through cooperation and construction of ideas.

\subsection{Research Method}

A qualitative content analysis of the responses written in answer to the questions posed in the course forum.

\subsection{The Research Procedure}

Analysis of the dialogs and examination (followed three different courses in three years) of the contribution of metaphors in consideration of the allegory along the time axis (in the transition from the past to the future). 


\subsection{Research Tools}

In order to identify thinking processes and practical use of educational philosophy, students were asked to answer an open question in the online forum. The requirements were as follows: to read the text, interpret it, link it to contemporary education and examine the extent of its relevance to our post-modern era. The answers were analyzed by content themes and key issues that were raised by students. Atlas software was also used.

\subsection{Research Population}

- 150 students, studying in Year 1 (a cross-stream course), an online compulsory course as part of undergraduate studies in education and teaching of a B.Ed. degree at the Ohalo Academic College.

- 3 different classes/groups of students in three years sequence 2014-2016. All were committed to learn and respond to the tasks and questions that appeared in the online learning system.

- Population characteristics: Demographic characteristics: living in the north of the country especially in Galilee and Golan Heights. A multi-cultural population: Jews, Muslims, Druze and Circassians. Gender-Two-thirds of women and one third men.

\subsection{Hypotheses}

The "Allegory of the Cave" constitutes an important source for developing a critical, creative thinking. The use of augmented metaphors enables the clarification of professional attitudes and moral perceptions amongst student-teachers, educators of the future.

\section{Metaphorical thoughts from the Past Implementing the Future}

Plato's "Allegory of the Cave" is recognized as one of the allegories that inspire discourse and thinking in many fields of knowledge. This canonical text deals with the departure from the darkness of the cave, i.e. chains, ignorance and illiteracy to the sunlight that symbolizes enlightenment, change and innovation. The liberation process embodies risks both from the exposure to the "developing" sun (the risk of blindness) and danger from those who prefer to remain in the darkness and harass those who assert/expose the existence of the light. The allegory has inspired creative works in cinema, literature and the arts, and yet its meaning for future educators remains enigmatic.

Within the framework of studies concerning the subject: "Education according to the great philosophers of ancient Greece", this text was chosen as the first to learn and analyze in the course forum. The text was uploaded onto the online course site in a Hebrew translation. The students were asked to read the text, to interpret it, to link it to contemporary education and examine the extent of its relevance to our post-modern era. 
In order to motivate the process of online dialog construction in the spirit of the 21st century, the following question was asked (For three consecutive years) on the course forum: "in your opinion, is the "Allegory of the Cave" still important in the modern era or is it no longer relevant? Explain your opinion?

This question, one of many, was presented on the forum during the semester. Received the highest number of reactions (120 responses), and erase an alert discussion that arose reflective thinking concerning the question. These processes played an important role, helping the students to construct the optimal image of the $21^{\text {st }}$ century teacher within the teacher training process.

The interesting dialog, exactly as written, word for word, served as units of content. Their analyses and different meanings are presented below. Using Fiske's semiotic model (1990) (Figure 1) we examined cultural influence on the deciphering of the text. According to Fiske (1990) "decoding is a sort of recreation of the text", conducted against the background of the complex cultural baggage of the decoder. He asserts that multiple meanings provide the key to understanding human communication. Polysemic meanings are created through interactions between different types of readers and different types of texts in various circumstances. Fiske describes this model of communication as a (seemingly) cyclic process of creation and exchange of meanings.

The manner used to decode communication is derived from the dataprocessing procedure, i.e. the collection, interpretation and integration of data in the context of decision-making (Tushman \& Nadler, 1978; Vlaar, 2008). The data-processing procedure relates to the acquisition of knowledge and behavioral results that follow the processing of this new knowledge, such as decision- making. This procedure provides standards helping people to evaluate, process, and then integrate information that they receive from the outside world with internal information.

It was found that when examining identical information, different people use different conceptual rules in their thinking processes, decision-making and management of interpersonal relations.

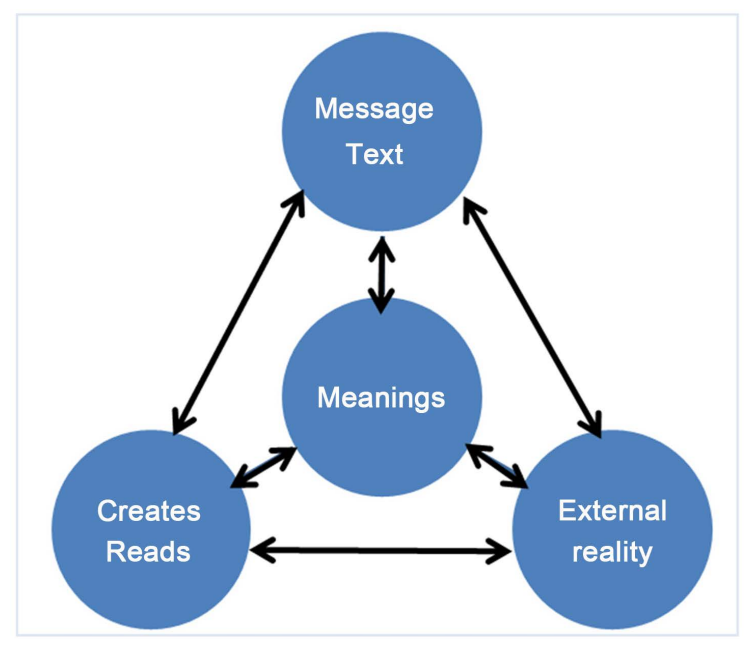

Figure 1. Fiske's model of semiotic communication. 
In the present context, the data processing procedure described in Figure 2 above, explains how the students integrate the information that they have drawn from the ancient text with their own internal knowledge, especially in an unconventional environment like the class's virtual forum. The process is performed in the "black box", i.e. the human brain and results are expressed in the students' statements.

The data processing model of Kaniel and Arazi (Kaniel, 2003) allows us to present a visual picture of the data-processing procedures that the students conduct from the stage of reading the allegory until their final deduction of conclusions, expressed in their definition of the present-day role of the teacher. The proposed model is based on Kaniel and Arazi's model (see Figure 3) and suggests the reason for the students' choice of particular parts of the allegory and not others, for example: consideration of the teacher's role but no consideration of the danger overshadowing their life during the teaching/exposure of the reality.

Moreover, the students' interpretation of the allegory facilitated understanding concerning the way in which the text is seen in the students' eyes today. Since it is impossible to understand the allegory as it is, the reader is required to interpret the images and their activities in the text. An example of this is the description of the images' behavior in the allegory that reinforces the reader's allegoristic sense that this behavior is seemingly contrary to direct logic. In the current case study we can see that metaphors are a very important toll in associating with an unfamiliar idea or a complex one. It could help achieve a better understanding of complex ideas.

The text of the "Allegory of the Cave" is constructed as a dialog. With its covert and overt messages it arouses the student's response and personal interpret-

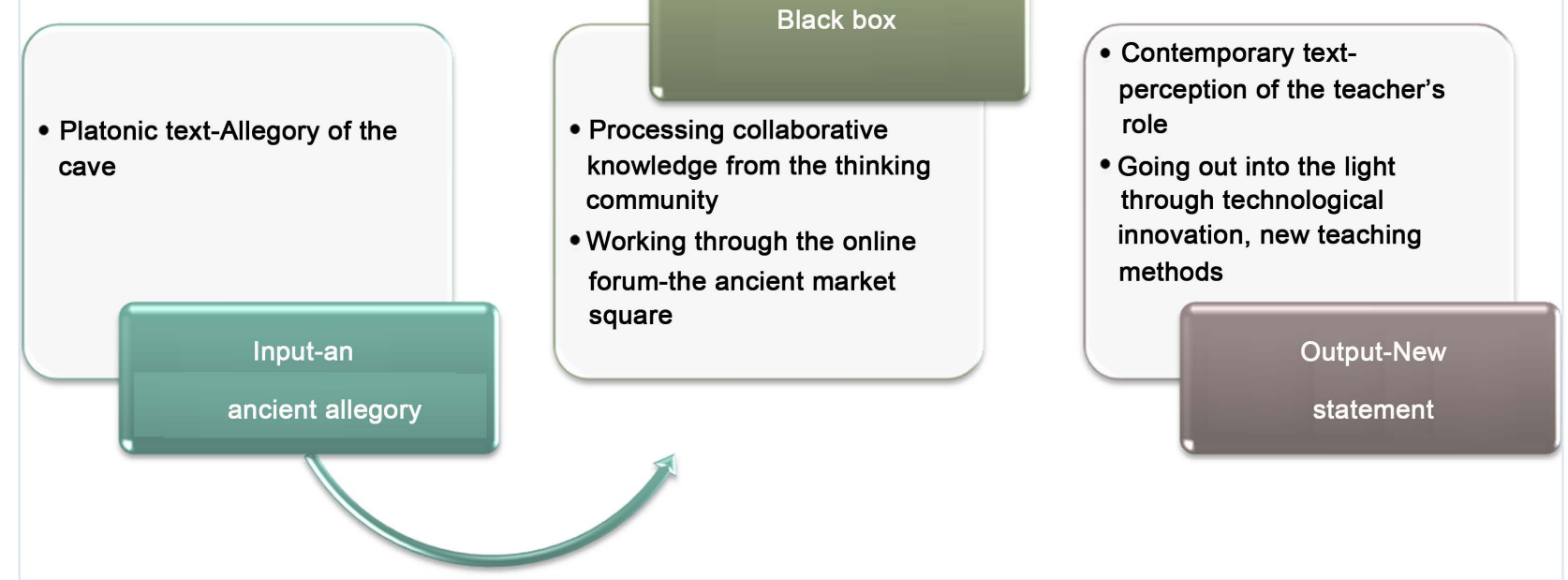

Figure 2. The brain as a "black box" during the data-processing procedure-processing procedure and personal decoding sequence. 

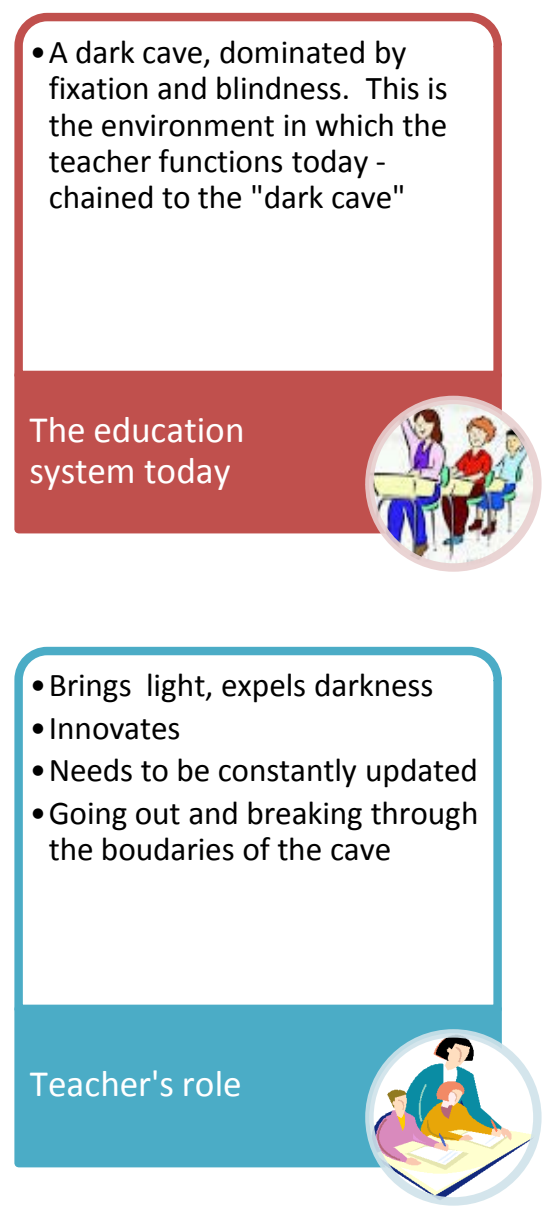

- Breaking through boundaries to a better and more effective pedagogic experience, through the acceptance and assimilation of new teaching strategies, thinking outside the box and use of different technologies as progressive means for teaching and learning methods

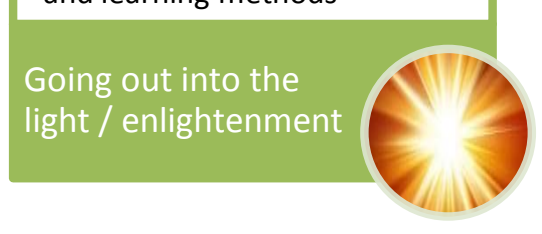

- Fixated, very fearful of coping with the unknown, even if it is enticing like the sunlight

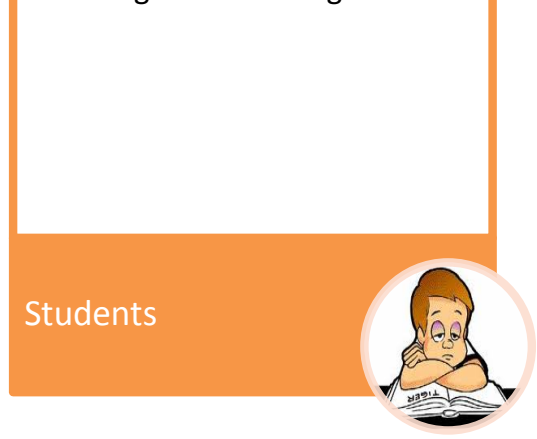

- The light outside the cave, variation of teaching methods; motivation to develop and to update oneself. On the other hand negative influence may be created

Technology
- The cave's boundaries analogous to the education system

-Analogy for a society bound by cables

- Boundaries of the fixation

- Practices, traditions, ways of thinking

\section{The cave's}

boundaries

Figure 3. Summary of prominent images and metaphors derived from analysis of the propositional content of the forum.

tation and their desire to share their thoughts and insights with the forum. It is remarkable to see how an ancient text creates interesting intrapersonal and interpersonal interactions that mainly revolve around the perception of the teacher's role within the education system in the modern era. Moreover it is surprising to see how an allegoric tale from the 5th century BC leads students to associations that create a context for the delineation of present-day needs in technology-assisted teaching. In fact, Plato succeeds in arousing the motivation of present-day students to act, perhaps this was his original intention from the start and the message that he wanted to transmit to his readers when he wrote the "Allegory of the Cave".

It seems that, beyond the Platonic allegory the students created a narrative of their own, appropriating the allegoric tale to create meaning associated with the modern education system and their future professional role. In this process students used mainly the first level of common learning out of the three levels: sharing, cooperating, and collaborating in accordance to their personal preferences and the situation. This basic level of sharing enables learners exchange ideas and share dialogue and other learning deliverables, so that they can enjoy, learn from them, and give feedback. The benefits of this cooperative level derive from the ability to transfer and accessibility of information, and getting feedback 
on it.

A large part of the interpretation revolves around the axis of teacher-student relations, so that each component of the ancient story was associated with a parallel in the reality of their professional lives. Moreover, they took the moral of the story one step forward, identifying perceptions, insights and responses to reduce gaps that exist in the education system and modify educational activity. As a result of their reflective thinking processes, the students were inspired to propose solutions and motivated to crystallize a declarative statement. This can be defined as a cognitive-conscious process, as the students, who will be the teachers of the future, work through the decoding of the allegory. Working together they constructed insights regarding the desirable professional method for work in their classes, alongside suggestions for suitable solutions to issues of teaching and learning posed by the 21 st century, although at present this remains solely at the conscious declarative level.

We analyzed the narratives written by students in relation to the Cave by content categories as presented below.

\section{Analysis of Responses and Statements}

\section{The significance of the allegory:}

the answers to the question "Is the allegory important even in our modern era?" indicates that most of the students recognized the significant importance of the text and its relevance even today, despite the fact that the allegory relates to a group of prisoners imprisoned and shackled since their childhood in a gloomy cave, who are unaware of the outside world.

The teacher-student interaction interpretation for the allegory-this was perceived by most of the students as very meaningful and was repeated with different nuances during the discussion, for example:

"I interpreted the allegory like most of the students, by relating to the teacher-student relationship. In my opinion, the ideal teacher is a teacher who acts to create constructive teaching, for whom each day is a new day and this is also so for his teaching method ... so that students will learn to think further, learning much from discussions, developing skills such as the culture of speaking, and dialog between students."

From the metaphor of the chains-to an interpretation of fixation-in contrast to the word "chains" that often appeared in the text, in the online dialogs (the text's interpretation) the students often used the term: "fixation". The question therefore arose: why was the word chains given almost no attention while the word fixation became the dominant metaphor? One possible interpretation is that the words "cave" and "chains" were seen as representing a sense of "stagnated thinking" in the education system and the teachers assumed that this feeling of stagnation was projected onto the students and consequently affected their motivation. The following are some of the responses on the forum relating to chains and fixation.

“... the allegory, as I see it, clarifies/ the view of those teachers who are stuck 
in their thinking and are unwilling or afraid to liberate themselves from their old teaching methods, and to recognize that there are new, better methods, more effective, that see the child at the center and that are open to responding to the students' opinions and feelings."

“... the cave's boundaries limit the thoughts of the 'fixated' teacher, who is not willing to escape beyond those boundaries and prefers to teach in the traditional manner, while the teacher who sees the light is the teacher who allows themselves to break through the boundaries, to arouse the child's curiosity and to be open to new aids that are effective and good for today."

"... The cave represents the thoughts of the "fixated stagnant" teacher, and the continued use of the old teaching method, despite the fact that technology and the modern era have many advantages.

"Future teachers should get out of their fixation and be more open to innovation, to new techniques that will increase students' effective interesting thinking, that will expand their horizons and enlarge their curiosity.

About the teacher's role-examples of statements relating to perceptions of the teacher's role:

“... as future teachers we need to continually develop our teaching methods, to always stimulate the students' curiosity and interest. Not to be stuck with particular methods rather to continually evolve and develop our teaching methods."

We as teachers must leave the "darkness"- the less interesting learning methods that are less likely to lead to shared learning ... and as it were we should leave the cave with new teaching, and different and interesting methods."

"I think it's important that the teachers should not be stuck, that they will be open to innovations and new ideas, and this will awaken the children's curiosity and motivation to learn ... the teacher should focus on technological development and use it with alternative methods in order to arouse students' curiosity and desire to develop and learn new ideas. The allegory of the cave highlights the role of the educator as someone who helps students to turn their gaze in the right direction and to overcome the obstacles as was done in the allegory. The role of the educator is to help but he cannot do this for them unless he himself takes on the role of liberator."

This last assertion can be linked to the deep metaphorical meaning of the metaphors "chains" and "fixation"

Fixation-Freud (1962) defined fixation as the obsessive attachment to a person or object. Fixation takes place when a person remains stuck in a particular stage, since they have not succeeded in resolving the crises that characterize this stage (ibid.), leaving the individual focused on this stage and unable to move onto the next. In this state, a person cannot rid his mind of an incorrect picture of the situation, that is inconsistent with reality, and they become stuck in that particular developmental stage. According to Freud, fixation is a sort of constricting thinking process, creating restricted and defined thinking patterns that do not allow the individual to see beyond this. Fixation symbolizes what is old, ancient and traditional and its legs are planted in the past, this is outdated 
thinking or thinking that has frozen in contradiction to the dynamic spirit of time.

Since the research population included student teachers studying teaching and education it can be assumed that they had been exposed to this Freudian concept during their studies in the "Introduction to Educational Psychology" course. Yet, most of the responses relate to a sort of conservative and traditional "fixation of thinking".

It is fascinating to see how the allegory of the cave and the decoding of the metaphor "chains/cables" and "fixation", as delaying factors, influences students' perceptions even today. They were able to conduct an online dialog between themselves, to take meanings from ancient times (the 5th century BC), and with a touch to the keyboard to take those meanings with them out of the "cave" and to pass as if through a time tunnel to the dazzling light of abundant pixels and smartphone applications, the Internet and other gadgets that enable learning fit for the 21st century. In this process, it is clear that the students formed a logical connection between "leaving the cave" and the teacher's present-day role as an educator, one who transmits knowledge, creating curiosity, mediating between the student and the new information and inspiring motivation for learning among their students.

The following responses show how the "Allegory of the Cave" allowed the students to form links between the metaphor of "going out into the light" and "exposure to the world outside the cave" and the teacher's perspective and role in the 21 st century. The use of innovation and progress towards the future and the teacher's assistance for their students "release" the student and allow them to "think outside the box", "not to remain fixated", and to "alter perceptions".

The student shared the view that learning involves an active process of knowledge construction, and that teaching is about supporting and upholding that process rather than simple transmission of knowledge from teacher to student (Duffy \& Cunningham, 1996), branching out into different meanings and creating a shared dialog-in the present case online dialog-within a community of learners.

The following are additional examples illustrating the students' interpretation and the process and construction of the dialog:

"The allegory of the cave is very important and highlights how important it is to think outside the box." "We as future teachers need to know and remember that we have to develop for 'the world outside the cave', understanding that it will not always be a simple process to change perceptions and thinking processes that they have always known". We need to see this as a challenge and not to give up and remain fixated in a particular type of thinking. Instead, we should to recognize that there are various paths that the world offers, meaning that we should use various teaching methods that will stimulate interest".

"I feel that the allegory does not reflect the reality of our lives. In the eternal dichotomy between black and white there is a range of tones. Sometimes we leave the cave but we are still chained to our habits and the way of thinking that 
we have assimilated in the cave, sometimes also in the reality outside the cave we again enchain ourselves to the feeling of dizzy freedom granted to us by the world outside."

"in my opinion, Plato in his allegory chose intentionally to exaggerate things in order to emphasize the stagnation in which some of the people were stuck. Even in our lives, we witness groups of people fixed in their closed perceptions in a radical way, which does not allow them to see that there is another reality if they will just agree to turn their heads. Thus, I think that the allegory of the cave describes our situation today in a very special way. I think that the most interesting point is that although Plato's allegory was written over a thousand years ago, the situation that it describes reflects our present reality. Could it be that the gap described in the allegory remains as it was then until today or have there been changes, deterioration and growth?"

"The allegory of the cave is important in our times, since the allegory speaks about education and the lack of education, so that within the cave there is a lack of education and this is the basic state of humanity. The chains represent the fixation of restricted knowledge. The role of education is to free us from the chains of this fixation, from prejudices, from feelings, release us from situations that bind us to lies and mistakes. And success depends on educating man for his life."

The above quotations show that the "Allegory of the Cave" stimulated the development of different directions of philosophical thinking among the students. Tension between old and new approaches relating to teacher-student relations, was expressed in the students' statements. The question: "who is the future educator" led the students to ponder "how should the teacher's development be expressed when they leave the cave?" "How should innovation and development of learning-teaching methods assisted by new technologies be implemented, while breaking away from old traditional methods?"

The students' responses link the metaphorical world with the real world and the past with the present and especially with the future. We found that they consolidated opinions and insights concerning the role of the teacher and educator, defining him/her as one who should "release the prisoners" from the cave, while they also examined the moral meaning of the teacher's role. Lastly, they used reflective thinking about teacher training processes that they experienced during the academic year.

The decoding and interpretation of texts through dialog has been awarded consideration in various research studies:

Tadmor (1997) defines dialogical education as an influential, shaping event that occurs between teacher and student who jointly foster a community of autonomous subjects, equal in value and liberated. The learners observe, think and search for meaning together, as they conduct discussion and communicate and form intellectual and emotional human contact.

The cultural-literacy model suggests that in order for individuals to understand text they should learn about the background that influenced the author of the text. Valsiner (2007) indicated that personal systems of terminology develop 
from socio-cultural systems of meanings adapted for the individual, allowing individuals to create meanings for their lives, for their world and their connection with it. In other words, dealing with texts supports processes of personal identity development.

Hirsch (1987) claimed that in order that individuals can understand written texts, they need to be familiar with the underlying core of cultural knowledge, since individuals, who communicate with their peers in a particular culture, assume the existence of a common background and culture that they share. This information is seen as "obvious" for authors and so they do not include it in their texts. Thus in order to understand and communicate in an effective manner, the individual in any culture is required to share access to knowledge and meanings that stem from that culture. Banks (2004) claimed that teachers can help learners to develop their identities, through identification with, empathy with and critical reading of the text or through integration of contents with their own situation. Texts representing knowledge that influences the cultural identity of the learners can support the confirmation of their cultural identities and thus encourage them to conduct dialog. Readers identify the arguments that are meaningful for them in the text, at the level of their personal or professional identity, and locate themselves as allies or opponents of the text.

Côté and Levine (2002) who designed a complex understanding of identity in the Western world, claim that students' qualities and virtues allow them to think about issues of identity through their consideration of meanings in texts with cultural value. They note that humans have a natural narcissistic tendency to focus on themselves and to see themselves as the center of the world. Thus, it is important to develop a sense of belonging to a moral code, to a society, to a culture and to a nation and if appropriate to encourage students' ability to change and forgo their preconceived personal, historical, cultural and social identities.

Content analysis of the students' statements identified several categories of images and metaphors that characterize the following subjects (Figure 3).

\section{Discussion and Conclusions: From Prisoners of the Past to Future Educators}

The students created original, innovative and modern interpretations for the ancient Platonic text. They saw the "Allegory of the Cave" as a textual "starting point" constituting a trigger for thinking from which they marched towards the future in a quest for personal and professional self-discovery and conducted deep interpretation relating to the education system. The metaphorical "cave" and the departure from it seemed to them to represent a transition from the past to the future. Going out into the light, the sun, and departing from the cave's darkness out into the world symbolized the revelation of knowledge, insight and the use of knowledge to create new thinking, alternative pedagogy, and teaching-learning "outside the box".

It is also interesting to discover that the decoding of the texts led to the novel interpretations described above, an "ending" that was significantly different in 
meaning from Plato's original ending. In the conventional interpretation for the Platonic allegory some scholars reason that the messenger is murdered and the prisoners remain in darkness. In the students' decoding of the allegory in the online dialog, the difficulties and meanings at the end of the process developed in a positive operative direction and the students learnt to cope with the lesson in an empowering manner, suggesting practical solutions in the personal dimension and also in the systemic dimension.

When the students were asked to continue to "describe the connection between the prisoners of the past and teachers of the future", their responses shown below succinctly described their feelings. Most likely similarities in the lists of required skills to the 21st century and the list below of new interpretation are no coincidence. The importance stems from the fact that the students reached these conclusions as a result of learning process both independent and collaborative. Figure 4 relates to the process that they underwent on the forum.

The students noted: "there is a sequence of development along the axis of time. The prisoners of the past who were imprisoned in a particular place and in a particular way of thinking, did not at first try to think in a different way. They did not try to change their reality and accepted their life as it was and coped with it. But, with time they began to think, to try to change the existing situation, to discover new things and eventually they succeeded in performing changes. And

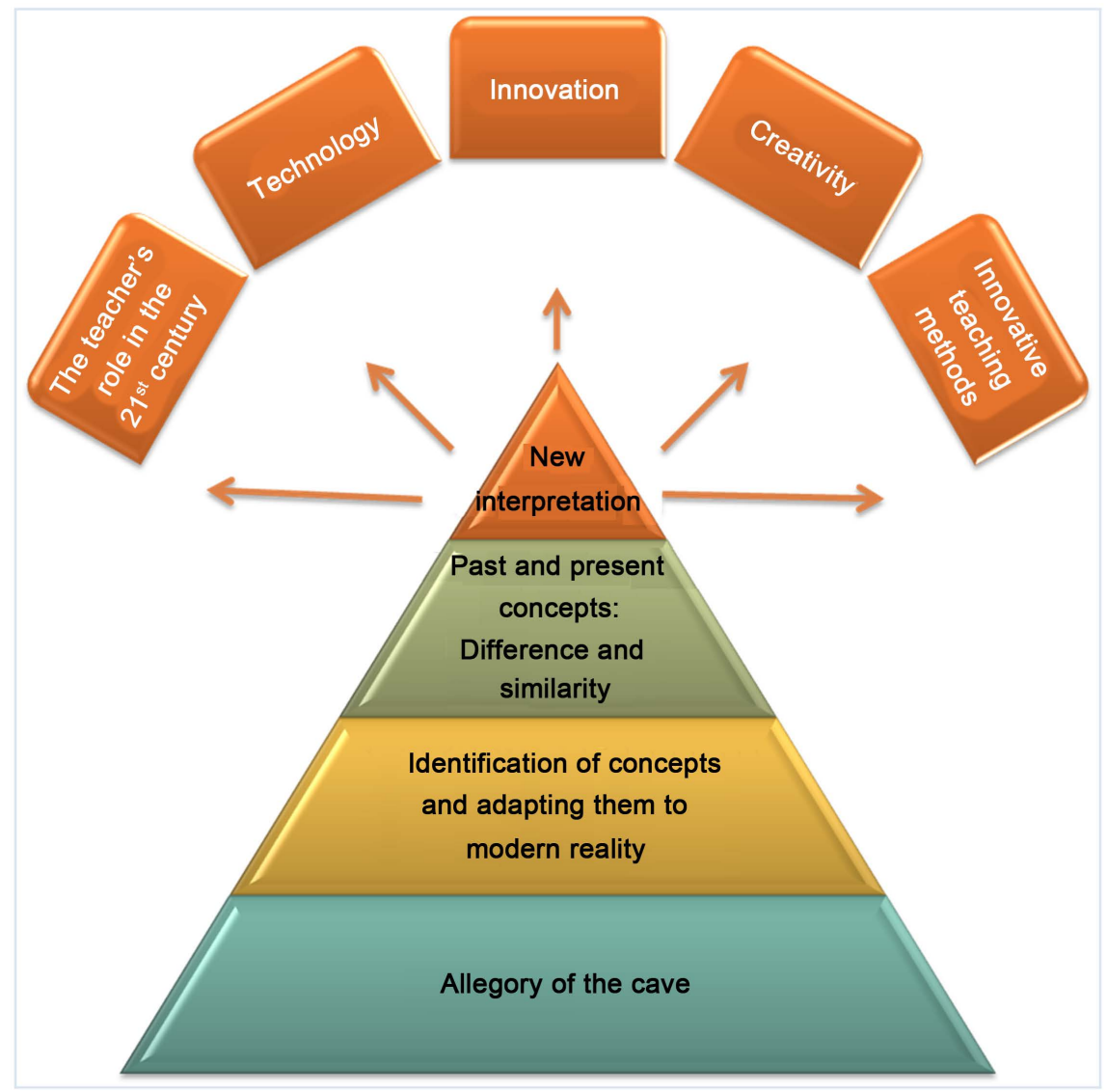

Figure 4. The decoding model and its products. 
this resembles teachers who as educators should take this message and transfer it to their students in order to transform them into creative people and to bring them to a state whereby they will always follow things up and won't be satisfied only with what already exists. The teachers can in this way offer students effective learning that helps them to look at things in an alternative way and this helps them to overcome difficulties and to continue with their lives and to understand that nothing is inevitable and that they can change their reality."

"We can draw a link along the time axis between "prisoners of the past" and "educators of the future" since in my opinion, in the "Allegory of the Cave", for the prisoners of the past, the departure towards the light, to the revelation of knowledge, stems from the same motivation, a sort of impulse that the prisoner in the cave feels that he must go out and be exposed to the world that he saw from behind the shade, the aspiration to know, to satisfy curiosity. And we also, as the educators of the future, should be pushed to expose new and different methods and always to search for what is new and for beneficial change. Although there is change over time, the goal remains the same: to expose and know what is new and more effective."

"We can create a continuum of development along the axis of time, meaning that the prisoners of the past were imprisoned within their representation of particular things and they did not question their knowledge and think about things and why they were this way or that; rather they accepted their representation in a fixated manner. During the development along the axis, it can be seen that they began to investigate and to try to understand what was behind each thing. When the people of Israel left their slavery in Egypt, they accepted the old representation of things as obvious without understanding or knowledge, yet after leaving Egypt they always asked why and wanted to know what underpinned the acts of the Lord and his messengers. In other words they did not accept the representation of things by the Lord and his messengers as obvious. They investigated things and wanted to know the reason for them-this resembles future educators who need to aspire to educate their students to investigate, to create, to construct knowledge and not to fear being exposed to knowledge that differs from the knowledge they already know. They should stimulate them and support them to construct knowledge and not simply to 'pour it in' to them."

Kozminski and Kalvier (2010) indicate that a stance of inquiry can assist dialog about the teacher's professional identity. They cite Cochran-Smith and Lytle (1999) who suggest that throughout their lives teachers should act together as an investigative community, maintaining continuous dialog. This dialog will help to construct local knowledge concerning teaching, creating personal theories concerning practice and testing these theories in comparison with other research. Investigative communities conduct both social and political activity, and raise questions concerning teaching routines and the ways in which knowledge is created and awarded use and respect. An investigative stance allows critical discussion about the teacher's professional identity and the role of teachers in creating educational change as individuals and as a group leading towards what Marcia and Fraser (2008) dubbed "identity achievement". 
To summarize, using innovative tools and methods in learning process of an ancient text allow technology evolve creative thinking on and contemporary understanding of the text. During this process students (with an awareness to the process or lack of it) also were exposed to the importance of technological innovation to current learning practices and processes, exposure which means a lot to future teachers which are expected to be leaders in their field Most of the students felt that the "Allegory of the Cave" is a very meaningful text, even today. Most of them identified an analogy in the allegory to the restrictions of the present day education system. They identified with the need to be released from chains and fixation in their use of teaching methods, and advocated an approach that encouraged the use of novel means and advanced technologies as part of the teaching process. The results of the forum discussion include clear and sharp definitions of the "do" and "don't do" rules. The "don't do" rules include warnings to teachers lest they remain fixated, chained in their way of thinking, imprisoning their students and adhering to traditional and outdated teaching methods; in other words, remaining in the dark obscurity of the cave.

On the other hand, the "do" rules are more encouraging: innovation, consideration of students' needs, propagation of values and adaptation to the changing reality of the post-modern era; progress and development of principles and new directions of thinking while promoting creativity and curiosity; development and implementation of new teaching methods (especially dominant in the online discourse) while demonstrating ability to create interest and to be open to new technologies and sophisticated, adapted teaching means. It is interesting to discern that the teacher-student interface was perceived as a challenging, complex space facilitating meaningful learning through metaphorical thinking that motivates thinking, dialog, a community of thinkers and a community of learning. Undoubtedly, discussions on the forum added a significant layer to bridge between what was old and what was new and contributed to the departure of the cave prisoners and to the construction of future educators. Without a doubt Metaphors are a great tool for creating impact and making something memorable and thought-provoking.

\section{References}

Anderson, J. H. (2008). Reading the Allegorical Intertext: Chaucer, Spenser, Shakespeare, Milton. New York: Fordham University Press. https://doi.org/10.5422/fordham/9780823228478.001.0001

Banks, J. A. (2004). Multicultural Education: Historical Development, Dimensions, and Practice. In J. A. Banks, \& C. A. M. Banks (Eds.), Handbook of Research on Multicultural Education (2 ed., pp. 3-29). San Francisco, CA: Jossey-Bass.

Birenbaum, M. (2002). Online Forum. Collected Writings. Tel Aviv: University of Tel Aviv. (In Hebrew) https://education.tau.ac.il/profile/biren

Cochran-Smith, M., \& Lytle, S. L. (1999). Relationships of Knowledge and Practice: Teacher Learning in Communities. Review of Research in Education, 24, 249-305. http://rre.sagepub.com/cgi/content/short/24/1/249 https://doi.org/10.2307/1167272

Côté, J. E., \& Levine, C. G. (2002). Identity Formation, Agency, and Culture: A Social 
Psychological Synthesis. Mahwah, NJ: Lawrence Erlbaum.

Dorman, J., \& Fraser, B. J. (2009). Psychosocial Environment and Affective Outcomes in Technology-Rich Classrooms: Testing a Causal Model. Social Psychology of Education, 12, 77-99. https://doi.org/10.1007/s11218-008-9069-8

Duffy, T. M., \& Cunningham, D. J. (1996). Constructivism: Implications for the Design and Delivery of Instruction. In D. H. Jonassen (Ed.), Handbook of Research for Educational Communications and Technology. NY: Macmillan Library Reference USA.

Fiske, J. (1990). Introduction to Communication Studies. London (EC4P 4EE29 West 35th Street), New York, (NY 10001). 2nd ed. (This Edition Published in the Taylor \& Francis e-Library, 2002.C 1990. ISBN 0-203-13431-1 Master e-book ISBN ISBN 0-203-17746-0 (Adobe eReader Format) ISBN 0-415-04672-6 (pbk) 2nd Edition).

Freud, S. (1962). Three Essays on the Theory of Sexuality (Trans. James Strachey). New York: Basic Books.

Hirsch Jr., E. D. (1987). Cultural Literacy: What Every American Needs to Know. Boston, MA: Houghton Mifflin.

Johnson, D. W., \& Johnson, R. (1989). Cooperation and Competition: Theory and Research. Edina, MN: Interaction Book Company.

Kaniel, S. (2003). Actions of the Mind: The Fundamentals of Education for Thinking. Tel Aviv: University of Tel Aviv and Ramot Publishers. (In Hebrew)

Karacapilidis, N. (Ed.) (2009). Solutions and Innovations in Web-Based Technologies for Augmented Learning: Improved Platforms, Tools and Applications. Hershey, PA: IGI Global.

Kozminski, L., \& Kalvier, R. (2010). Construction of Teachers' and Teacher-Educators' Identity in a Changing Reality. Tel Aviv: Mof et Institute. (In Hebrew)

Levi, D. (2006). Action Research in Practice. Philosophical and Methodological Affinities between Action Research and the Qualitative Research Paradigm. Tel Aviv: Mof et Institute. (In Hebrew)

Marcia, J. E., \& Fraser, S. (2008). Identity, Psychological Development and Counseling. Paper presented at the National Conference for School Counselors: Construction of Identity and Multiple Identities in a Changing Era, Israel: Haifa University.

Pringle, R. M. (2002). Developing a Community of Learners: Potentials and Possibilities in Web Mediated Discourse. Association for the Advancement of Computing in Education, 2, 218-233.

Rich, J. (1996). The Heterogeneous Class. Ramat-Gan: Bar-Ilan University.

Sharan, S. (1989). Cooperative Learning in Small Groups: A Review of Methods and Research. Studies in Education, 51-52, 87-114. http://www.jstor.org/stable/23394290

Tadmor, I. (1997). Dialogical Education. In I. Kashti, M. Arieli, \& S. Shelanski (Eds.), Lexicon of Education and Teaching (pp. 177-178). Tel Aviv: Ramot and University of Tel Aviv.

Tredway, L. (1995). Socratic Seminars: Engaging Students in Intellectual Discourse. Educational Leadership, 53, 26.

Tushman, M. L., \& Nadler, D. A. (1978). Information Processing as an Integrating Concept in Organizational Design. Academy of Management Review, 3, 613-625.

Valsiner, J. (2007). Culture in Minds and Societies. New Delhi: Sage.

Vlaar, P. (2008). Contracts and Trust in Alliances: Discovering, Creating and Appropriating Value. Cheltenham, UK; Northampton, MA: Edward Elgar. https://doi.org/10.4337/9781848443006

Vygotsky, L. S. (1978). Mind in Society. Cambridge, MA; London, England: Harvard University Press. 
Submit or recommend next manuscript to SCIRP and we will provide best service for you:

Accepting pre-submission inquiries through Email, Facebook, LinkedIn, Twitter, etc. A wide selection of journals (inclusive of 9 subjects, more than 200 journals)

Providing 24-hour high-quality service

User-friendly online submission system

Fair and swift peer-review system

Efficient typesetting and proofreading procedure

Display of the result of downloads and visits, as well as the number of cited articles Maximum dissemination of your research work

Submit your manuscript at: http://papersubmission.scirp.org/

Or contact ce@scirp.org 